\title{
DESCARTES Y EL ESCEPTICISMO
}

Laura Benítez G.

Instituto de INVESTIGACIONES Filosóticas

Universidad Nacional autónoma de México

\section{Introducción}

Aunque no puede decirse que Descartes sea, en el uso correcto del término, un escéptico, no se puede dejar de reconocer que desarrolló varios argumentos escépticos que resultan particularmente interesantes para el análisis del conocimiento humano.

Por diversos motivos que voy a exponer a lo largo de este trabajo, no comparto la idea de quienes opinan que la argumentación escéptica cartesiana es o bien un artificio especulativo inútil, o bien una argumentación no pertinente para el estudio y la comprensión de los problemas epistemológicos. Estoy convencida, por el contrario, de que, visto desde dentro de la teoría cartesiana, se trata de un momento metodológico fundamental para el establecimiento de lo que Descartes consideró como el verdadero conocimiento; y, desde fuera, esta argumentación arroja luz sobre problemas tan importantes como el de nuestro conocimiento dél mundo externo, o el de la posibilidad de la fundamentación de cualquier clase de conocimiento. La estrategia que voy a seguir es tratar de iluminar la problemática en torno a dos argumentos escépticos cartesianos: el argumento del dios engañador y el del sueño, a la luz de dos perspectivas metodológicas totalmente diferentes, proponiendo sus alcances y limitaciones en el examen y la interpretación del problema. Me parece un ejercicio interesante en vista de que la precisión en el análisis argumentativo de Loewer rebasa la discusión cartesiana y esto acarrea problemas a su interpretación pero, por otra parte, el enfoque historiográfico contextual o, para hablar en términos de Rorty, la reconstrucción histórica de Popkin si bien no se sitúa fuera de la problemática cartesiana, no es un instrumento de análisis que pueda mostrar matices y diferencias insoslayables para una cabal comprensión del problema.

El detalle de estas perspectivas y sus consecuencias para la interpretación de la argumentación cartesiana, así como mi propia 
versión del asunto, se irán aclarando, espero, en los diversos apartados de este estudio. ${ }^{1}$.

\section{La ruta escéptica en la metodología cartesiana}

Como se sabe, la atmósfera en que se desarrollan las Meditaciones es una atmósfera escéptica en un sentido peculiar. ${ }^{2}$ Descartes trata de responder a los argumentos escépticos más fuertes, llevándolos hasta sus últimas consecuencias, valiéndose de la propia ruta escéptica para poder establecer la posibilidad del conocimiento y la existencia de las cosas, de Dios y del alma. ${ }^{3}$

Entre las formulaciones escépticas de Descartes dos han llamado la atención de los autores contemporáneos: la del dios engañador y la del sueño. Esta última se precisa en la Primera Meditación de la siguiente manera:

Pero pensando en ello cuidadosamente, recuerdo haber sido engañado a menudo, mientras dormía, por ilusiones parecidas. Y deteniéndome en este pensamiento veo tan claramente que no hay en absoluto indicios concluyentes, ni señales suficientemente seguras, mediante las cuales se pueda distinguir claramente la vigilia del sueño, que me ha pasmado, y mi asombro ha sido tal que casi me persuade de que duermo."

El problema que se maneja es la necesidad de encontrar fundamento seguro al conocimiento sensible, ya que:

Todo lo que he recibido hasta el presente como lo más verdadero y seguro, lo he aprendido de los sentidos o por los sentidos: si he experimentado algunas veces que estos sentidos son engañosos, es prudente no fiarse nunca enteramente de aquellos que nos han engañado una vez.

Descartes no desacredita totalmente el conocimiento sensorial, sólo previene sobre el engaño, ya por el límite real del alcance perceptual, con respecto a lo muy pequeño o lo muy alejado, ya por una razón mucho más importante, que es la imposibiliđad de contar

1 Todas las citas de Les Méditations (Med.) y de Le Discours de lo Méthode (Disc.) pertenecen a la edición de $C$ urres de Descartes de Adam \& Tannery. Leopold Cerf, París, 1913. Las traducciones son mías.

2 "Pongo en primer lugar las razones por las cuales podemos dudar generalmente de todas las cosas y particularmente de las cosas materiales, al menos en tanto que no tengamos ningunos otros fundamentos de las ciencias que aquellos que hemos tenido hasta el presente." Med., AT, IX, 9.

3 Véase Med., AT, IX, 12.

4 Med., AT, IX, 15.

5 Med., AT, IX, 14. 
con un criterio que permita distinguir entre lo real y lo fantástico. El argumento del sueño se sitúa en este nivel. Va más allá de las dudas sobre el alcance de los sentidos, pues se trata de cuestionar aun las percepciones sensibles más claras y distintas mostrando la insuficiencia del criterio de claridad y distinción en relación con nuestro conocimiento del mundo externo, ya que no saber si se está dormido o despierto es incompatible con el conocimiento del mundo en torno.

Por su parte, el argumento del dios engañador representa un avance más radical en la duda metódica, pues afecta no sólo al mundo externo sino también las verdades más simples y evidentes que se originan en el propio entendimiento.

De todos modos hace mucho tiempo que tengo en mi espíritu cierta opinión, relativa a que hay un Dios que todo lo puede y por el cual he sido creado y producido tal como soy. Así, ¿quién me podría asegurar que este Dios no haya hecho que no hubiera ninguna tierra, ningún cielo, ningún cuerpo extenso, ninguna figura, ningún tamaño, ningún lugar y que no obstante yo tuviera las sensaciones de todas estas cosas y que por todo ello no me parecieran existir de ningún otro modo que como los veo? Y también, como he juzgado que los otros se equivocan incluso en las cosas que piensan que saben con la mayor certeza, podría ser que Él hubiera querido que yo me engañara todas las veces que hago la suma de dos más tres o que enumerara los lados de un cuadrado, o que juzgara sobre cualquier cosa aun más fácil, si poderıus imaginar algo más fácil que esto. 6 .

Este argumento pone en crisis no sólo el conocimiento sensible o el racional, sino el propio criterio de verdad, de manera que resulta patente la insuficiencia de los fundamentos de todo conocimiento. Sin embargo, la idea no es postular la imposibilidad del conocimiento sino la debilidad de los criterios comunes, y aun del propio criterio de claridad y distinción, si no se pueden dar razones o garantías más sólidas que lo refuercen.

En suma, el argumento del dios engañador se refiere a la insuficiencia del criterio de claridad y distinción para establecer, en general, el conocimiento indubitable; el del sueño, a esta misma carencia con respecto al conocimiento del mundo externo. En otra forma, la de la duda cartesiana, no saber si se es engañado o no por un dios engañador es incompatible con el conocimiento. A la par, no saber si se está dormido o despierto es incompatible con el conocimiento del mundo externo. Nótese de paso que, por un lado, no saber si se está dormido o despierto y por ello dudar, implica que

${ }^{6}$ Med., AT, IX, 16. 
sé que si estoy despierto puedo conocer y sé que si duermo no puedo conocer; el problema es que, dentro del propio nivel de la percepción sensible, no es posible determinar si se está dormido o despierto y Descartes buscará la salida en otro nivel. Del mismo modo, no saber que no hay un dios engañador implica que sé que si no lo hay puedo conocer, pero șé que si lo hay entonces no puedo conocer. La insistencia en el saber en ambos casos se debe a que deseo mostrar que las formulaciones cartesianas no son prototípicas del escepticismo en vista de que Descartes no sostiene ni la indeterminación frente a las opciones ni la equipolencia de las opiniones. Lejos de buscar la feliz imperturbabilidad mediante la suspensión del juicio frente al conocimiento o su imposibilidad, Descartes avanza de lo que podríamos llamar premisas cognoscitivas negativas, o saber de las razones que impiden el conocimiento, a premisas cognoscitivas positivas, o saber de las razones que garantizan el conocimiento. En forma más simple, en su programa epistemológico Descartes va del saber que no se sabe al saber que se sabe. De todo esto se desprende que las propuestas más firmes a las que estratégicamente Descartes debe aspirar son: (1) saber que no existe un dios engañador y (2) saber que no se está dormido.

Esta dos propuestas no representan sino los requisitos fuertes del conocimiento en Descartes y a menudo se manejan como imposibles de satisfacer.

La cercanía en la formulación y estrategia de ambos argumentos no se debe únicamente al hecho de que Descartes trate de postular que conocer es saber con plena indubitabilidad. Estos argumentos son interesantes no sólo en vista de este objetivo central, sino porque en su construcción se pretende utilizar toda la fuerza del escepticismo para rechazarlo.

Descartes rechaza el escepticismo respecto del conocimiento del mundo externo desde la Primera Meditación, a través de la causalidad. ${ }^{7}$ También lo rechaza en la Sexta Meditacion a través de la continuidad y la coherencia de la experiencia. ${ }^{8}$ Además, muestra la inconsistencia de un escepticismo radical que atenta contra el propio criterio de verdad al señalar las contradicciones que encierran los conceptos del dios engañador y del genio maligno, las cuales se anuncian desde la Primera Meditación ${ }^{9}$ y a cuyo análisis

\footnotetext{
7 "De todos modos es necesario al menos argüir que las cosas que se nos representan en el sueño son como cuadros o pinturas que no pueden formarse sino a semejanza de algo real y verdadero, y que asi, al menos, estas cosas generales, los ojos, la cabeza, las manos y todo el resto del cuerpo, no son cosas imaginarias sino verdaderas y existentes." Med., AT, IX, 15.

8 Véase Med., AT, IX, 71 .

9 Véase Med., AT, IX, 17.
} 
dedica prácticamente la Tercera Meditación. No obstante su rechazo directo al escepticismo, la duda metódica despertó una doble sospecha: ¿cómo es que siendo ajeno al escepticismo puede Descartes ser realmente más escéptico que los escépticos?, ¿acaso el uso del arsenal escéptico no implica por sí mismo una buena dosis de escepticismo real y no didáctico o metodológico? Esta fue la duda que asaltó a los contemporáneos de Descartes, que Popkin reseña ampliamente y de la cual nos ocuparemos más adelante.

\subsection{Los argumentos escépticos cartesianos}

Como sabemos, el postulado cartesiano de que "sólo lo que se percibe clara y distintamente es verdadero" se mantiene a lo largo de las Reglas para la dirección del espíritu y se pone en crisis en las $\mathrm{Me}$ ditaciones en vista de que la percepción clara y distinta, que desde luego es siempre en Descartes percepción del espíritu, no garantiza en sí misma su indubitabilidad.

En este primer conocimiento no hay nada sino una clara y distinta percepción de lo que conozco, la cual no sería suficiente para asegurarme que es verdadero si pudiera suceder que una cosa que concibo clara y distintamente fuera falsa. Y por tanto me parece que ya puedo establecer como regla general que todas las cosas que concebimos muy clara y distintamente son todas verdaderas. De todos modos, antes he recibido y admitido muchas cosas como muy ciertas y manifiestas, las cuales, sin embargo, reconocí posteriormente que eran dudosas e inciertas. ¿Cuáles eran pues esas cosas? Eran la tierra, el cielo, los astros y todas las otras cosas que percibo por medio de mis sentidos. ${ }^{10}$

Así, el criterio de claridad y distinción se muestra como condición necesaria pero no suficiente del conocimiento indubitable. Lo que se descubre tras la argumentación escéptica cartesiana es el criterio de verdad como indubitabilidad. ${ }^{11}$ Los argumentos escépticos cartesianos actúan, en alguna forma, como hipótesis complementarias que ayudan a garantizar la indubitabilidad de lo conocido al cuestionarlo.

La estrategia en el desarrollo de ambos argumentos es semejante: 1. Si yo no sé que no existe un dios engañador, no sé que ' $x$ ' $o$ ' $y$ '.

2. Si yo no sé que no estoy dormido, no sé que tal o cual.

1.1. Existe un dios engañador, ergo no sé que $p$.

2.1. Estoy dormido, ergo no sé que $p$.

10 Med., AT, IX, 27.

11 “... debo examinar si hay un Dios en cuanto la ocasión se presente, y si encuentro que lo hay, debo examinar si puede ser engañador, porque sin el conocimiento de estas dos verdades no veo cómo pueda estar nunca seguro de ninguna otra cosa." Med., AT, IX, 29. 
La pregunta obvia es: ¿por qué saber de la no existencia de un dios engañador es condición necesaria del conocimiento?, y paralelamente, ¿por qué se requiere saber que no estoy dormido como condición que garantiza mi conocimiento del mundo en torno? Descartes responde que, por una parte, la percepción clara y distinta puede bastar para el conocimiento actual, pero la memoria de la percepción no garantiza suficientemente la indubitabilidad del conocimiento; por otra parte, de manera más radical, la percepción clara y distinta, de primer nivel, no es condición suficiente del conocimiento, precisamente por lo que esencialmente muestran las hipótesis escépticas cartesianas, a saber, que sólo colocados en una perspectiva que rebase nuestra justificación cotidiana acerca de lo que creemos saber, lo cual se traduce en plena indubitabilidad, podemos hablar de verdadero conocimiento. La percepción clara y distinta, sin reforzar, no excluye la posibilidad de nuevas razones que me hagan dejar de creer que $p$.

Llama la atención la formulación negativa de estos principios del conocimiento; así, requiero saber que no existe un dios engañador y que no estoy dormido, pero la contraparte positiva de esta formulación es obviamente saber que realmente se sabe y ésa sería la condición del conocimiento en Descartes. ¿Cómo estoy seguro de que sé? Este saber no puede surgir de la mera aserción "sé que estoy en lo correcto", "sé que estoy despierto", por fuerte que sea el sentimiento que esté detrás. Para saber que estoy en lo correcto o que estoy despierto requiero saber, según Descartes, que no me engaño. La formulación positiva del saber que no me engaño es saber que sé o, en terminología más moderna, la formulación en lógica epistémica $K K p$ (yo sé que sé que $p$ ). En relación con el problema que nos ocupa, este principio no es mera repetición vacua si recoge lo que Descartes entiende por conocer, y es la expresión abreviada de la certeza cognoscitiva toda vez que se ha superado algún nivel de duda, ya sea la duda sobre la percepción del mundo externo, con la seguridad de que no se duerme, ya sea la duda sobre cualquier proposición verdadera con la seguridad de que no hay posibilidad de un engaño sistemático.

Por otro lado, la reconstrucción contemporánea del saber que se sabe en el principio $K K p$ permite entender, según Loewer, que el saber que $p, K p$, expresa que no hay dudas de primer orden sobre $p$, no existen razones para dudar de lo que se cree o sabe, al paso que, el saber que se sabe que $p, K K p$, expresa que no hay dudas de segundo orden, esto es, no tengo motivos para dudar que realmente conozco que $p$.

First order reasons for doubting $\mathrm{p}$ are reasons for doubting the truth 
of p. Second order reasons for doubt are grounds for doubting that the reasons one has for believing $\mathrm{p}$ are sufficiently strong. ${ }^{12}$

De acuerdo con esta explicación, el criterio de claridad y distinción de primer nivel, basta para eliminar las dudas de primer orden pero no para desechar las de segundo orden. Por clara y distinta que sea una proposición o percepción del mundo externo siempre puedo dudar de la validez de las razones que me llevan a creer algo. Así, ¿qué razones tengo para creer que estoy despierto y juzgo de la realidad y no de la fantasía?; y de nuevo, i qué razones tengo para creer que cualquier proposición, aunque sea muy evidente, como $2+3=5$, no es el producto de un engaño sistemático? Aquí, lo que se pone en duda no es tal o cual proposición aislada, o tal o cual proposición concreta, sino todo un sector del conocimiento, ya del conocimiento sensible, ya del conocimiento deductivo, y a lo que apunta Descartes con estos argumentos escépticos es a la fundamentación de esos dos sectores del conocimiento. Si yo no sé que estoy dormido, ¿cómo discrimino entre mis percepciones reales y las fantásticas? Similarmente, si yo no sé que existe un dios engañador, ¿cómo evitar la posibilidad de falsificación de cualquiera de mis proposiciones? Los argumentos escépticos cartesianos buscan poner a prueba y reforzar los fundamentos tanto del conocimiento sensible como del racional, y están obviamente en relación estrecha con lo que Descartes entiende por conocer, que Loewer reconstruye de la siguiente manera:

$A$ sabe que $p$ si y sólo si:

$A$ cree que $p$

$p$ es verdadera;

$A$ percibe clara y distintamente que $p$;

si $q$ es una proposición incompatible con el saber de $A$ sobre $p$, entonces $A$ sabe que $q$ es falsa.

En esta reconstrucción es obvio que los tres primeros requisitos se refieren a saber que $p$ y el cuarto a saber que se sabe que $p$. Así, este último requisito es fundamental porque expresa precisamente qué clase de razones para dudar quiere eliminar Descartes para establecer un conocimiento verdadero. Sólo cuando ya sé que el dios engañador es incompatible con mi conocimiento de una proposición, puedo, al probar que no existe, hablar de la verdad de esa proposición. De igual modo, sólo cuando sé que estar dormido es incompatible con saber algo acerca del mundo externo, puedo, al demostrar que no lo estoy, hablar de la percepción sensible como 
real. En caso contrario me hallo siempre en la duda y no puedo rebasar el escepticismo.

Loewer trata de reconstruir el argumento cartesiano en un sistema de lógica epistémica, contraparte del modal $T$.

Primero simboliza dos principios que considera fundamentales para la teoría cartesiana del conocimiento.

1. El principio $P$ (principio de conocimiento),

$$
[-k-q \cdot k(q \supset-k p)] \supset-k p \text {. }
$$

Si no sé que no $q$ y sé que si $q$ entonces no sé que $p$, entonces no sé que $p$.

Este principio expresa de manera sucinta y formalizada lo que se ha venido diciendo para los dos argumentos escépticos. En " $q$ " se puede sustituir, "no existe un dios engañador" o "no estoy dormido".

2. El principio $Q$ (principio de percepción),

$$
\text { 口(Jp } \supset \text { p). }
$$
$p^{14}$

Si percibo clara y distintamente que $p$, entonces, necesariamente,

Tomando en cuenta estas dos definiciones de percibir y conocer que Loewer atribuye a Déscartes, la reconstrucción más interesante sería la siguiente:

$$
[-K-g \cdot K(g \supset-K p)] \supset-K p .
$$

Si yo no sé que no existe un dios engañador y sé que si existe un dios engañador entonces yo no sé que $p$, entonces yo no sé que $p$. Según Loewer, la fórmula anterior es equivalente lógicamente a $K p \supset K K p$, si yo sé que $p$, entonces yo sé que yo sé que $p$, y es un argumento válido en la lógica epistémica S4 en la que es válido el principio: $K P \supset K K{ }^{15} .^{15}$

Loewer aclara que:

i) a Descartes le bastaría con decir: $g \supset-k p$, si existe un dios engañador entonces no sé que $p$, porque para él se trata de una verdad debida a la luz natural de la razón;

ii) uno puede preguntarse cómo un argumento escéptico puede aceptar una premisa de conocimiento (yo sé que si tal entonces tal).

11 Ibid., p. 168.

15 Ibid., p. 170. 
Según Loewer, es un hecho que todo argumento escéptico admite premisas cognoscitivas, siempre que no sean sino conceptos lógicos. Con todo, también señala que aunque se trata de un concepto lógico, no es una proposición analítica, porque no deriva de la naturaleza del dios engañador que $2+3$ no sea igual a 5 , o que no haya materia, etc.; lo que es parte de su naturaleza es que si existe se puede cuestionar que las proposiciones sean verdaderas.

En mi opinión, este problema se puede ver aún más claramente si se sustituye el argumento anterior por el del sueño:

$-k-g:$ yo no sé que no estoy dormido;

$k(g \supset-k p)$ : sé que si estoy dormido entonces no sé que $p ;$

$-k p$ : entonces no sé que $p$.

No deriva de la naturaleza de estar dormido que no haya Luna o materia, etc., sino que lo que es parte de la naturaleza del sueño es que al estar dormido se puede cuestionar todo mi conocimiento del mundo externo.

No saber que no existe el dios engañador, o no saber que no se duerme, es no tener razones para afirmar nada. Así, por claro y distinto que sea mi conocimiento de $p$, lo que no tengo son razones suficientemente sólidas que no puedan ser removidas por otras que falsifiquen esta creencia en tanto subsista la posibilidad del dios engañador, el genio maligno o el sueño, para las diversas clases de conocimiento. No hay, en un sentido cartesiano radical, auténtico conocimiento por adecuados que sean mis conceptos o fuertes que sean mis creencias, mientras no se rebasen estas posibilidades de engaño.

\subsection{Niveles del escepticismo cartesiano}

La reconstrucción de la argumentación cartesiana que hace Loewer, presenta algunas dificultades, además de las que él mismo señala, como vimos en la seccion anterior. En mi opinión, el argumento formalizado no traduce cabalmente la preocupación de Descartes. En cuanto a la primera premisa: "Si yo no sé que no existe un dios engañador no conozco que $p$ ", o bien, "Si yo no sé que no estoy dormido, no conozco que $p^{n}$, expresan una situación de duda radical que equivale, en el segundo caso, a no tener criterios para distinguir entre la realidad y la fantasía, y en el primero a la situación, aún más desventajosa, de no poder distinguir entre la verdad y el error. El hilo de la argumentación cartesiana prosigue: porque aunque tenga la percepción clara y distinta de $p$, no tengo buenas razones 
para afirmar que conozco $p$. Este es el caso del ateo que no sabe que un dios engañador no existe y por tanto no conoce que $p$.

Así, no niego que un ateo pueda conocer clara y distintamente que los tres ángulos de un triángulo son iguales a dos rectos; sólo sostengo que no conoce mediante una ciencia verdadera y cierta, porque todo conocimiento que puede volverse dudoso no debe llamarse ciencia, y puesto que suponemos que éste es un ateo, no puede estar seguro de no ser engañado en absoluto en las cosas que le parecen ser muy evidentes como se mostró más arriba; e incluso como puede ser que esta duda no se le presente en absoluto en el pensamiento, puede ser, sin embargo, que le surja si la examina o le es propuesta por otro, y nunca estará fuera del peligro de tenerla si primero no reconoce a Dios. ${ }^{16}$

A partir de estas consideraciones parece que la reconstrucción más natural sería: $-k-g \supset-k k p$, porque aunque el ateo tiene la percepción clara y distinta $J p$ del teorema de que la suma de los ángulos de un triángulo es igual a dos ángulos rectos y por ello $k p$, conoce que $p$, cree pero no tiene conocimiento verdadero, científico, pues no tiene garantía de su creencia, esto es: $-k k p$.

Por otra parte, al introducir la hipótesis del dios engañador deben destacarse dos aspectos:

i) señalar que se trata de una mera hipótesis, de un instrumento epistemológico y no de una existencia ontológica en la que alguien pueda efectivamente creer o no creer; ${ }^{17}$.

ii) que esta hipótesis funciona, en el nivel epistemológico, cancelando el principio de claridad y distinción como principio suficiente del conocimiento. Si existe un dios engañador no hay posibilidad de distinguir entre la verdad y el error, esto es, se cancela el criterio de verdad porque la función del dios engañador es justamente desvincular lo claro y distinto de lo verdadero. Ahora podemos preguntarnos, ¿por qué le es necesario a Descartes concebir al dios engañador? La radicalidad de la empresa consiste en darse cuenta de la incompatibilidad de la hipótesis con el conocimiento. La sombra del dios engañador destruye la posibilidad de conocimiento verdadero, en el sentido de saber fuerte, de saber que se sabe, de tener razones firmes para creer lo que se cree. La afirmación del dios engañador niega el conocimiento, pero su negación lo afirma. La estrategia

16 Med., AT, IX, 111.

17 Aunque algunos autores como M. Gouhier y F. Alquié han señalado que la suposición del dios engañador es una hipótesis metafísica y la del genio maligno un procedimiento metodológico, el carácter de hipótesis instrumental que tiene el dios engañador en el seno de la duda metódica y sus características como concepto lo hacen una útil herramienta epistemológica. 
es por tanto destrozar la hipótesis metodológica bajo el peso de la prueba ontológica de Dios como imposibilidad de engaño. En el sistema cartesiano, al paso que el concepto de Dios se fortalece, la hipótesis del engañador se desvanece per imposibile, y se restituye el criterio de verdad ahora con el respaldo o garantía divina.

Porque primero, reconozco que es imposible que me engañe jamás, ya que en todo fraude y engaño se encuentra cierta clase de imperfección. $Y$ aunque parezca que el poder de engañar es un signo de sutileza o de poder, en cualquier forma querer engañar es testimonio sin duda de debilidad y de malicia. Y por tanto, esto no puede encontrarse en Dios. ${ }^{18}$

Dentro de la línea escéptica pero con un peso epistemológico diferente, Descartes propone el argumento del genio maligno.

Supondré entonces que hay no un verdadero Dios, que es la fuente suprema de la verdad, sino una cierta clase de genio maligno, no menos astuto y engañador que poderoso, y que emplea todo su ingenio en egañarme. Pensaré que el cielo, el aire, la tierra, los colores, las figuras, los sonidos y todas las cosas exteriores que vemos no son sino ilusiones y engaños, de los que se sirve para sorprender mi credulidad. ${ }^{19}$

De este argumento Loewer propone la siguiente reconstrucción, que revela con claridad la diferencia de grado entre el escepticismo más radical que encierra el concepto del dios engañador, y un escepticismo menos fuerte que se manifiesta en cada instancia o caso particular de conocimiento al suponer la existencia de un genio maligno.

$-k-d:$ no sé que no existe el genio maligno.

$k[d \supset(b p \supset-p)]$ : sé que si existe el genio maligno, entonces si yo creo que $p$, entonces $-p \cdot-k p$. Luego no sé que $p^{20}$

Descartes resolvió súspender el juicio, no creer que $p$ o que $-p$, para derrotar parcialmente al genio maligno.

Me consideraré como si no tuviera ni manos, ni ojos, ni carne, ni sangre, como si no tuviera ningún sentido, pero creyendo falsamente tener todas estas cosas. Permaneceré oḅstinadamente ligado a este pensamiento, y si por este medio no está en mi poder llegar al conocimiento de ninguna verdad, al menos está en mi poder suspender el juicio. ${ }^{21}$

Med., AT, IX, 43. 
Pero la manera que le pareció a Descartes más efectiva para cancelar esa susposición, fue el establecimiento del cogito.

Pero hay un no sé qué engañador muy poderoso y muy astuto que emplea toda su industria en engañarme siempre. No hay, sin embargo, ninguna duda de que soy, si me engaña; y que me engañe tanto como quiera, no podrá jamás hacer que no sea nada en tanto yo piense ser alguna cosa. ${ }^{22}$

$\mathrm{Al}$ advertir las características del concepto "genio maligno", Loewer propone que, si efectivamente cada vez que yo creo algo como verdadero puede ser que no sea sino el producto de un engaño, si aquéllo en lo que creo es precisamente en la existencia del genio maligno como un ser que puede engañarme en cada instancia particular, entonces el genio maligno no existe. En principio al creer en el genio maligno se puede asegurar su no existencia, pero, ise puede sostener al mismo tiempo que hay tal engendro engañador y que uno cree que existe? Loewer atribuye a Descartes esta inconsistencia, que se revela en la siguiente reconstrucción:

$$
B d \cdot B[d \supset(B d \supset-d)] \cdot{ }^{23}
$$

Yo creo que existe el genio maligno y creo que si el genio maligno existe, entonces, si creo que existe, no existe. La idea es que no puedo creer que existe algo que por definición cada vez que yo creo que existe, puesto que mi creencia es falsa, no existe.

Aquí deseo hacer las siguientes observaciones. Para Loewer, Descartes quiere asegurar la no existencia del genio maligno creyendo que existe. Y se pregunta si Descartes puede, consistentemente, creer que el genio maligno existe dadas sus características. Mi particular sentir es que en ningún momento' se trata de una creencia. Descartes no cree en el genio maligno, se trata de una suposición hipotética. La idea es, más bien, primero, que aun cuando fuera posible (que no lo es) la existencia de tal engendro, no puede engañarme si suspendo el juicio (primer aspecto que no recoge la reconstrucción de Loewer); y segundo, el genio maligno no es una entidad metafísica en cuya existencia se puede o no creer, sino que es una estrategia epistemológica, de tal suerte que no resulta sino un concepto autoanulable. Advierta, parece decir Descartes, que si concibe al genio maligno como existente, tiene que negarlo al mismo tiempo, por lo que se evidencian su imposibilidad metafísica y su inconsistencia lógica. Me parece que Descartes se sitúa más allá de la contradicción; la pone simplemente al descubierto para 
socavar al escepticismo que deriva de no poder confiar en lo claro y distinto como criterio suficiente de verdàd, ya que a la percepción clara distinta puede corresponder el error si se supone al engañador. Finalmente, Descartes no cree, ni quiere que creamos, en el genio maligno, sino que trata de llevar la situación de duda lo más lejos posible. ¿Qué pasa si supongo que aun las verdades matemáticas que me parecen más claras y distintas no son, finalmente, sino errores, ya que puede haber un ser poderoso que se complazca en engañarme constantemente? Descartes pone en tela de juicio las razones de segundo orden para creer que $p$. Yo creo que $p$, pero si supongo al genio maligno, ¿cómo justifico mi creencia en $p$ ? La fórmula no es, me parece: crea usted en el genio maligno porque al hacerlo lo va usted a anular; la idea es más bien: considere usted una tal existencia demoniaca, ¿le parece que puede ser metafisícamente viable un ente tal, o al menos lógicamente consistente? Ahora tiene usted buenas razones para saber que no existe, que no puede existir y hasta que es necesario que no exista si la indubitabilidad es el criterio último del conocimiento. Frente a la inviabilidad de los engendros, Descartes quiere mostrar la viabilidad de lo real y, más aún, del ente realísismo. En efecto, un ente viable está en relación directa con su posibilidad lógica. Si no es posible ni siquiera como concepto, queda descartada su realidad. Pero la inviabilidad conceptual apunta también en un sentido más fuerte. Así, no sólo es que analíticamente en el concepto de un dios engañador no se contenga su existencia, en vista de que la existencia no es un predicado, sino que del análisis del concepto lo que se obtiene es la inconsistencia entre la omnipotencia, la omnisciencia, etc. que apuntan a la perfección, y el engaño sistemático que apunta a la imperfección. ${ }^{24}$

...este mismo Dios, digo, cuya idea está en mí, que posee todas estas elevadas perfecciones de las que nuestro espíritu puede tener alguna idea, sin por ello comprenderlas todas, que no está sujeto a ningún defecto y no contiene nada de las cosas que señalan alguna imperfección. De donde es evidente que no puede ser engañador puesto que la luz natural nos enseña que el engaño depende de algún defecto. ${ }^{25}$

El presupuesto detrás de esta forma de argumentar es el criterio de la concepción adecuada. El dios engañador no es posible como concepto y mucho menos es viable como ente metafísico. La dis-

24 «...es cierto que puesto que errar y equivocarse es una clase de imperfección, entre menos poderoso sea el autor que atribuyan a mi origen más probable será que yo sea de tal modo imperfecto que me engañe siempre." Med., AT, IX, 17.

25 Med., AT, IX, 41. 
tinción real se presenta nuevamente como el límite de la concepción adecuada. La estrategia es entonces sustituir la noción inadecuada del dios engañador (imperfecto), por la del dios cuya bondad en grado eminente no es consistente con el engaño y sí en cambio con la omnipotencia, la omnisciencia y demás perfecciones. El gran problema, como sabemos, es que por consistente que sea la noción del dios perfecto, la existencia se le sigue escapando. De ahí resulta que la garantía o razones de segundo orden para conocer que $p$ no sea tan absoluta o última como pretende Descartes. La garantía es relativa y se apoya tanțo en la superación del engaño sistemático al demostrar la inconsistencia del concepto del dios engañador, como en anular los efectos del engaño del genio maligno en cada caso particular, primero en forma restringida al suspender el juicio, ya que de hecho en ese estadio no se obtiene ninguna verdad; o mejor aún, derrotando al genio maligno mediante la evidencia del cogito. Visto así, las razones de segundo orden para creer, aunque firmes, estarían fundadas exclusivamente en mis capacidades cognoscitivas, en mi propia imperfección, esto es, en el alcance de mi intelecto y mi volición, que como facultades son enteramente adecuadas a mi ser de hombre. Naturalmente Descartes pretende bastante más que esta clase de conocimiento relativo haciendo que Dios garantice la verdad indubitable y la perfección de nuestras facultades de conocimiento. $^{26}$

En cuanto al nivel escéptico del argumento del sueño se limita a la percepción sensible, y Descartes considera que una vez resuelto el problema de la imposibilidad del dios engañador y de la inconsistencia del genio maligno, las razones de segundo orden para creer en el mundo externo se fundan en la propia perfección de Dios como ser no engañador. ${ }^{27} \mathrm{El}$ problema en este caso es que si saber que no estoy dormido es la condición última del conocimiento sensible y depende en efecto del dios no engañador, como tal existencia no se puede demostrar como Descartes propone, no tiene forma de distinguir entre el sueño y la vigilia, sino parcialmente a través de la causalidad y la coherencia, pues aun cancelando el engaño sistemático, jamás tendrá esa clase de garantía - absoluta - para saber que sabe que $p$ con respecto al mundo externo.

\section{Ubicación de Descartes frente al escepticismo}

26 Además experimento en mímismo un-cierto poder de juzgar, el cual he recibido sin duda de Dios, lo mismo que todas las otras cosas que poseo; $y$ como él no querrá engañarme, es seguro que me lo ha dado de tal modo que nunca pueda errar si lo uso como es debido. Med., AT, IX, 43.

27 Véase Med., AT, IX, 71-72. 
En la sección anterior intenté mostrar cómo a pesar de la nítida reconstrucción lógica que Loewer lleva a cabo, no recoge del todo la intención de las formulaciones escépticas de Descartes, que se puede resumir como presionar, hasta el último límite, la situación de dubitabilidad o intensificar las condiciones de la dubitabilidad a fin de poderla superar. Para aclarar mejor este problema vale la pena tomar un camino distinto al seguido hasta ahora. Se trata de la reconstrucción histórica, y naturalmente la pregunta más importante que surge es: ¿por qué Descartes toma la vía escéptica? Si anteriormente tratamos de ver qué importancia filosófica tiene su argumentación escéptica, ahora nos proponemos ubicarla frente al escepticismo de su tiempo. Al respecto hay diversas posiciones. El abate Francisco Para de Phanjas, según cita Popkin, comenta que:

Descartes enseñó a su siglo el arte de hacer nacer del escepticismo la certeza filosófica. ${ }^{28}$

El propio Descartes se vio a sí mismo como el vencedor de las dudas escépticas. No obstante, es importante aclarar cuál fue el papel de Descartes en términos de la crisis escéptica de su tiempo

... one finds that Descartes himself expressed great concern with the scepticism of the time; that he indicated a good deal of acquaintance with the Pyrrhonian writings, ancient and modern; that he apparently developed his philosophy as a result of being confronted with the full significance of the crise pyrrhonienne in 1628-29, and that Descartes proclaimed that his system was the only intellectual fortress capable of withstanding the assaults of the sceptics. ${ }^{29}$

En el cuidadoso estudio que Popkin dedica a la cuestión se hacen obvios los diversos aspectos del clima escéptico que le tocó vivir a Descartes. ${ }^{30}$ Conocedor de los nuevos pirrónicos y de la crisis que habían engendrado, Descartes quiere llegar a las bases más profundas del escepticismo y según Popkin la hipótesis del genio maligno sirve a tal fin.

But the next level, the demon hypothesis, is much more effective in revealing the uncertainty of all that we think we know. This possibility discloses the full force of escepticism in the most striking fashion, and unveils a basis for doubting apparently never dreamed of before. ${ }^{31}$

28 Richard Popkin, The History of Scepticism from Erasmus to Dezcartes, Assen Van Gorcum, 1964, p. 175.

29 ibid., p. 176.

30 Véase ibid., pp. 176 y ss.

31 Ibid., p. 182. El subrayado es mío. 
Como argumento escéptico, el del genio maligno tiene la posibilidad de socavar los fundamentos del conocimiento; no sólo del que procede de la opinión cambiante de los sentidos sino de los enunciados matemáticos más evidentes. Su fuerza escéptica estriba en que frente a semejante instancia falsificadora no sólo se distorsiona la información en cada ocasión particular, sino que se contaminan de duda escéptica los canales que nos proporcionan la información, esto es, nuestras facultades de conocimiento.

Any criterion, any test of the reliability of what we know is open to the question because either the standard or the application of it may be demonically infected. ${ }^{32}$

Mi ingenua certeza de saber que $p$ se ve fuertemente cuestionada pues en cada instancia particular puedo ser sujeto de engaño. Sin embargo, frente a Popkin hay que recordar que el argumento del genio maligno no es la instancia de argumentación escéptica más fuerte que Descartes usa. La consideración del dios engañador representa un nivel aún más profundo de escepticismo ya que, como vimos, en ese caso el engaño no resulta de la falsificación de instancias particulares de conocimiento sino de la imposibilidad de proponer un criterio de verdad que trae aparejada la supresión del conocimiento. Para Popkin el escepticismo que acarrea la hipótesis del genio maligno no sólo se extiende a las proposiciones sino también a nuestras capacidades o facultades de conocimiento. De otro modo, no tener razones para saber que $p$, es admitir que uno no puede conocer; así, se ponen en entredicho las facultades de conocimiento. Por esto dice Gilson que Descartes pasa de la crítica del conocimiento a la crítica de las facultades del conocimiento, o del nivel científico al propiamente filosófico. ${ }^{33}$ Lo que no queda claro ni en el caso de Gilson ni en el de Popkin es en qué plano de la crítica se sitúa Descartes al poner en entredicho la posibilidad misma de un criterio de verdad, la del conocimiento, e insinuar la absoluta irracionalidad. ¿Se trata acaso de un nivel archifilosófico? En mi opinión quien no reconoce diferencia entre el genio maligno y el dios engañador no ha visto con claridad la radicalidad de la empresa crítica cartesiana, y no entiende que los calificativos que Descartes se aplica a sí mismo se comprenden únicamente a la luz de esta gradación escéptica. De hecho, la siguiente afirmación de Popkin tiene más sentido en conexión con el dios engañador que con el genio maligno: 
In introducing the level of doubt, creating the possibility of the malin génie, Descartes overthrew the mathematical intuitionism of the Regulae as the foundation of all certainty. The crise pyrrhonienne had been pressed to its farthest limit. ${ }^{34}$

En suma, sin una clara noción de los niveles del escepticismo cartesiano es dudoso poder dar una explicación de cómo pueden superarse. En efecto, - lo que basta para superar las dudas que engendra el genio maligno, a saber, la evidencia del cogito, es totalmente insuficiente para librarnos del engaño sistemático del dios engañador; problema que para Descartes, al igual que el del mundo externo, no puede resolverse en el nivel epistemológico, sino en el ontológico, como quedó dicho más arriba. Esta clase de problemas hacen pensar que la mera historia contextual de la filosofía, o reconstrucción histórica, requiere del auxilio del análisis argumentativo. De manera más general, no son autosuficientes las diversas formas metodológicas para interpretar el pensamiento de un autor. En el caso del análisis argumentativo porque al ignorar el contexto puede fácilmente distorsionar la problemática original; y en el caso de la historia de la filosofía, porque al considerar los nexos entre.las teorías, sus condiciones genéticas y desarrollo, pierde de vista los matices de la argumentación. Además de que sin un instrumental apropiado, la reconstrucción de estos aspectos sutiles se dificulta enormemente.

\section{Descartes: ¿̇dogmático o escéptico?}

Después de haber propuesto los argumentos escépticos y los nivèles de escepticismo en que Descartes se mueve, lo menos que podemos esperar es un diagnóstico sobre la filosofía cartesiana. ¿Es Descartes un escéptico o un dogmático? En opinión de Popkin, ${ }^{35}$ lo que diferencia al escepticismo cartesiano del nuevo pirronismo es que:

1) al intensificar la duda en cualquier aspecto, por pequeña que sea, hasta el punto de considerarlo falso, Descartes procura estar en condiciones de separar lo aparentemente evidente y seguro de lo verdaderamente evidente y seguro;

2) el propósito del método conduce a muy distintos resultados. Como señala Para du Phanjas: "dudar como lo hizo Descartes no es ser pirrónico, es ser filósofo: no es embrollar la certeza humana, es consolidarla"; 
3) el propio Descartes afirma que los escépticos sólo dudan por dudar y siempre están indecisos, por lo que no extraen de ese método otra cosa que el permanecer la vida entera en el error y nunca están capacitados para salir de las dudas que han introducido en la filosofía.

Tal vez la mejor manera para determinar si Descartes es o no un escéptico sea, además de acudir a su propia concepción de la cuestión, apoyarnos en el análisis externo de lo que es el escepticismo y de cuáles son sus variantes para dar un diagnóstico más fundado sobre el caso cartesiano.

Si como refiere Ezequiel de Olaso, el escepticismo se caracteriza, más que por la duda, por la actitud que se tome para salir de ella, ${ }^{36}$ existirán, por un lado, diversas clases de escepticismo y, por otro, no toda duda será una duda escéptica.

Descartes establece muy claramente en la segunda parte del Discurso del método que:

Incluso no quise comenzar por rechazar de inmediato ninguna de las opiniones que se hubieran podido filtrar durante mi crianza y que no se introdujeron por medio de la razón, sin haber antes empleado buen tiempo en realizar el proyecto de la obra que había emprendido y en buscar el verdadero método para llegar al conocimiento de todas las cosas de que mi espíritu fuera capaz. ${ }^{37}$

Al anteponer ei método para buscar la verdad a la duda, Descartes muestra que:

1) no está dispuesto a suspender el juicio; más aún

2) está determinado a encontrar un sólido y firme criterio de verdad, $y$

3) la duda está subordinada a los dos primeros fines.

Frente al escéptico pirrónico o maduro, como lo clasifica Olaso, que ha logrado la tranquilidad del espíritu mediante la suspensión del juicio, Descartes es dogmático, ${ }^{38}$ pues toma la decisión no sólo

36 Ezequiel Olaso, Escepticismo e ilustración, Cuadernos de Historia de la ideas, Universidad de Carabobo, 1981, p. 23.

37 Disc., AT, VI, 17.

38 Uso el término dogmático no como opuesto a crítico, que es el uso más común, sino como opuesto a escéptico, y más particularmente, como Kant lo emplea cuando se refiere al sueño dogmático del cual lo despertó Hume, que implicaba creer que las cosas se pueden conocer en si y que todo el conocimiento es deducible a partir de primeros principios. 
de sostener tesis aisladas sino de constituir un cuerpo de conocimiento sobre el saber, una teoría epistemológica fundada en principios. Descartes no sólo no renuncia a la filosofía, sino que hace de la metafísica el fundamento último, sólido e indispensable de sus reflexiones. Dice Descartes:

No sé si debo detenerme en las primeras meditaciones que hice porque son tan metafísicas, y tan poco comunes, que puede que no sean del agrado de todo el mundo. Sin embargo, a fin de que puedan juzgar si los fundamentos que establecí son lo suficientemente firmes, me veo de algún modo obligado a hablar de ellos. ${ }^{39}$

El dogmatismo cartesiano se muestra contrario también a un escepticismo académico en que se da la suspensión intermitente del juicio, se permanece inmaduramente en la irresolución o la duda y se considera asequible sólo la probabilidad y no la verdad. En la segunda parte del Discurso refiere:

La mera resolución de deshacerse de todas las opiniones que se han recibido anteriormente durante la educación, no es un ejemplo que todos deban seguir; y el mundo está compuesto casi por completo por dos tipos de espíritus a los cuales no les conviene de ninguna manera. A saber, aquellos que se creen más hábiles de lo que son, no pueden impedir el precipitar sus juicios, ni pueden tener la suficiente paciencia para concluir en orden todos, sus pensamientos; de donde surge que si se tomaran alguna vez la libertad de dudar de los principios que han recibido, y se apartasen del camino común, jamás podrían tomar el sendero que es necesario para marchar más directamente y permanecerían perdidos toda su vida. Además, aquellos que teniendo suficiente razón o modestia para juzgar que son. menos capaces para distinguir lo verdadero de lo falso que aquellos por quienes pudieron haber sido instruidos, deben más bien limitarse a seguir las opiniones de los otros que buscarlas mejores por ellos mismos. ${ }^{40}$

De estas consideraciones podemos concluir:

1) sólo pueden ejercitar la duda en situación excepcional individuos excepcionales con una meta de conocimiento prefijada;

2) la situación de excepción hace referencia a contar con un proyecto previo de investigación o búsqueda de la verdad y a ejercitarla como un momento controlado por y subordinado a ese proyecto que, en última instancia, acabará por cancelarla, y

39 Dise., AT, VI, 31.

40 Disc., AT, VI, 15. 
3) la excepción en los individuos se refiere a un ejercicio de autocrítica que impide la sobreestimación o la falsa modestia. El ejercicio de la duda queda circunscrito a las almas templadas que en opinión de Descartes no abundan.

Nuevamente la duda aparece como un medio para el establecimiento de la verdad. Descartes reprocharía al escepticismo académico o inmaduro la irresolución o estar permanentemente en estado dubitativo, y el conformarse con criterios parciales y verdades probables. Así, dice:

No que imitase por ello a los escépticos que no dudan sino por dudar, y afectan estar siempre indecisos: porque al contrario, todo mi proyecto no tendía sino a reafirmarme y a rechazar la tierra movediza y la arena para encontrar la roca y la arcilla. Lo cual me parece que me resultó bastante bien, ya que al tratar de descubrir la falsedad o la incertidumbre de las proposiciones que examinaba, no mediante débiles conjeturas, sino mediante razonamientos claros y seguros, no encontré ningunos tan dudosos que no pudiera sacar alguna conclusión bastante cierta, aun cuando no hubiera sido sino que no contenían nada cierto. ${ }^{11}$

Si se concede que Descartes no es ni un escéptico académico ni un escéptico pirrónico, y por ende, se sospecha que no es en absoluto un escéptico, se hace urgente ubicar la duda cartesiana. Podría caracterizarse el escepticismo cartesiano como provisional o transitorio, superlativo y metodológico. Mi intención es demostrar que estas características van justamente en contra del escepticismo auténtico.

El carácter transitorio, estratégico o controlado de la duda, como se muestra en los pasajes antecedentes, es una preocupación constante de Descartes, al paso que en cualquiera de las formas de escepticismo sería simplemente inaceptable, porque o la duda se constituye en un estado permanente o se la cancela de manera acrítica. Por otro lado, en Descartes este carácter transitorio se subordina al método de donde la duda se presenta como estratégica o controlada, como una etapa superable en la búsqueda de la verdad, algo que ni los escepticismos cognocitivistas pueden proponer como punto de partida. En cuanto al carácter superlativo de la duda cartesiana, si tomamos al pirrónico como parámetro del mayor grado de escepticismo, el máximo nivel de duda correspondería justamente a la suspensión del juicio y la ataraxia. La empresa cartesiana no tiene ni un remoto parecido con semejante actitud. Los pirrónicos no buscan intensificar sino suprimir el estado de duda. Así, la consigna cartesiana de "dudar más que los escépticos" tiene sentido sólo 
en relación con los inmaduros académicos, pero con una diferencia muy clara de intenciones, a saber, dudar para no dudar, dudar para suprimir el estado de duda reemplazándolo por el de la certeza.

Por otra.parte, si el pirrónico encuentra la salida a la duda mediante la suspensión del juicio, Descartes la encuentra en la búsqueda de una garantía irrevocable de la verdad, según refiere en la Meditacion Quinta:

Pero después de que he reconocido que hay un Dios, puesto que al mismo tiempo he reconocido también que todas las cosas dependen de él, y que no es engañador, y que después de esto he juzgado que todo lo que concibo clara y distintamente no puede dejar de ser verdadero: aunque no piense ya las razones por las cuales juzgué aquello como verdadero, con tal que recuerde haberlo comprendido clara y distintamente, no se me puede presentar ninguna razón contraria que me haga ponerlo en duda y así cuento con una verdadera y segura ciencia. ${ }^{42}$

Descartes no es un escéptico, porque dudar no lo convierte eo ipso en un escéptico y mucho menos si el dudar es parte de un método de búsqueda de la verdad. Poner a prueba los fundamentos del conocimiento no es, por sí mismo, un camino escéptico sino una ruta crítica de la cual en la filosofía se dan múltiples ejemplos. Ya desde Sócrates sabemos que dudar no es sinónimo de indeterminación sobre las opiniones, o equipolencia de las razones, sino afán de análisis y punto de partida de la indagación. Por otro lado, ni por su planteamiento ni por sus intenciones la duda cartesiana es realmente escéptica. Si en efecto no basta dudar, o más en general, no basta el uso del instrumental escéptico para hablar de escepticismo sino que hay que remitirse a las actitudes del autor frente a la duda, es importante destacar que Descartes presenta tres desviaciones interesantes frente a los escepticismos consignados: 1) su afán de dudar más que los escépticos; 2) su determinación de no permanecer en la actitud indeterminada y oscilante de los escépticos, y 3) el superar la duda luchando filosófica y metafísicamente contra ella y no suspendiendo el juicio y con ello rechazando la metafísica o la filosofía en su totalidad. "Dudar para no dudar" no es una frase, sino que encarna en la resolución cartesiana de empujar la duda hasta sus últimas consecuencias a fin de demostrar las contradicciones que genera.

Además del carácter de la duda cartesiana es importante saber cuál es su función dentro del proyecto de investigación. Descartes pretende ir de la duda al conocimiento, pero ¿en qué sentido? 
No precisamente en el sentido de ir de la imposibilidad del conocimiento, actitud propiamente escéptica, a fundar su posibilidad, lo cual, por sí mismo, suena contradictorio. Sostener primero que no es posible el conocimiento para luego venir a decir que sí es posible; o que nada se puede conocer para luego establecer que prácticamente todo puede conocerse. Mi sugerencia es que el paso de la duda al conocimiento debe leerse como el paso del saber que no se sabe, al saber que se sabe; donde el peso está justamente en el primer saber. Lo que revela la duda cartesiana es que es prematuramente optimista afirmar que se conoce sin suficientes garantías o evidencias. Ser consciente de carencias, limitaciones, dificultades y objeciones es la sana pars destruens de la actitud crítica. Los argumentos del sueño, el genio maligno y el dios engañador ponen a prueba fundamentos, facultades y criterios de conocimiento, con objeto de mostrar la amplia gama de saber lo que no se sabe; esto es, ilustrar cuáles son las razones que hacen falta para poder sostener que algo se sabe. En este sentido estoy de acuerdo con los autores que, como Loewer, sostienen que para Descartes conocer es dar las razones para saber que $p$, esto es, saber que se sabe $p$. Sólo si se conocen o saben las carencias, es decir, que no hay o faltan razones para saber algo, puede intentarse legítimamente llenar estos huecos. Es verdad que Descartes se sale del ámbito epistemológico para buscar una garantía firme que resulta, por principio, discutible, pero no me toca ahora juzgar sobre los fundamentos metafísicos de la epistemología, ni sobre el resultado de esa empresa. Mi intención es simplemente mostrar que puede interpretarse la duda cartesiana como el saber de la carencia de razones para creer, que se propone como el paso previo a conocerlas. El conocimiento no sólo se revela como accesible sino que está presente en todas las formas cartesianas de la duda y es por eso que al reconstruir su argumentación no se ha podido prescindir de las premisas cognoscitivas. En cada argumento escéptico hay siempre una premisa que indica que yo sé que: si hay un dios engañador, o un genio maligno, o estoy dormido, entonces no sé. En estos casos el fondo del argumento revela que no se trata simplemente de no saber nada; se sabe que si una de estas instancias opera entonces no se pueden tener razones para creer, conocer, etc. No hay en los argumentos del método de la duda la intención de mostrar la imposibilidad absoluta del saber por medio de una equipolencia de opiniones, sino la de hacer ver, o hacernos conscientes de las carencias. Se trata, si se quiere, de premisas negativas pero cognoscitivas que nos permiten transitar del saber que no se sabe al saber que se sabe. 